\title{
Disponibilidade, Composição Botânica e Valor Nutritivo da Forragem de Pastos Con- sorciados, sob Três Taxas de Lotação ${ }^{1}$
}

\section{Roberto Giolo de Almeida2 ${ }^{2}$, Domicio do Nascimento Junior ${ }^{3}$, Valéria Pacheco Batista Euclides 4 , Manuel Cláudio Motta Macedo ${ }^{4}$, Dilermando Miranda da Fonseca ${ }^{3}$, Patrícia Amarante Brâncio ${ }^{5}$, Américo Fróes Garcez Neto 6}

RESUMO - Avaliou-se o efeito de três taxas de lotação, em pastagens de Brachiaria decumbens x Stylosanthes guianensis cv. Mineirão e de B. brizantha cv. Marandu x S. guianensis cv. Mineirão, sobre a disponibilidade, a composição botânica e o valor nutritivo da forragem. Adotou-se o delineamento experimental em blocos casualizados com os tratamentos no esquema de parcelas subdivididas, com duas repetições. Os tratamentos das parcelas constituíram um fatorial 2x3, sendo duas gramíneas (B. decumbens e B. brizantha cv. Marandu) em consorciação com $S$. guianensis cv. Mineirão e três taxas de lotação $(0,8 ; 1,2$ e 1,6 UA/ha), e as subparcelas, as épocas de amostragem (julho e outubro de 1998, correspondendo à época seca; janeiro e abril de 1999, correspondendo à época das águas). Foram utilizados bezerros Nelore, desmamados, com peso vivo médio de $138 \mathrm{~kg}$, no início do experimento. A disponibilidade de matéria seca (MS) da consorciação B. brizantha x Mineirão não variou entre épocas, com valor médio de $3470 \mathrm{~kg} / \mathrm{ha}$ de MS, enquanto que, para a consorciação B. decumbens x Mineirão, a média para o período das águas (3485 kg/ha de MS) foi superior a do período seco (3056 kg/ ha de MS). A disponibilidade da fração verde da gramínea diminuiu com a elevação da taxa de lotação. Durante a época das águas, verificouse maior proporção de gramínea, em relação à leguminosa, para uma taxa de lotação estimada de 1,17 UA/ha. As pastagens com B. decumbens apresentaram, de modo geral, maior proporção de forragem verde, de melhor valor nutritivo, associado a maior presença de leguminosa do que as pastagens com B. brizantha.

Palavras-chave: Brachiaria, digestibilidade, leguminosa, matéria verde seca, relação folha/colmo

\section{Availability, Botanical Composition, and Nutritive Value of Mixed Pasture Forages under Three Grazing Pressures}

\begin{abstract}
The effect of three stocking rates on intake, botanical composition and the nutritive value of the forage from pastures of Brachiaria decumbens with Stylosanthes guianensis cv. Mineirão and B. brizantha cv. Marandu with S. guianensis cv. Mineirão was evaluated. The experimental design was a randomized complete block with treatments subdivided into plots with two replications. The design of the plots was a $2 \times 3$ factorial with 2 grasses ( $B$. decumbens and B. brizantha cv. Marandu) in association with $S$. guianensis cv. Mineirão, three stocking rates $(0.8,1.2$, and 1.6 AU/ha), and two sampling periods, corresponding to the dry season (July and October 1998); and to the rainy season (January and April 1999). Weaned Nellore steers with an average initial weight $138 \mathrm{~kg}$ were used. The DM availability in the mixed pastures with B. brizantha did not vary between sampling periods and had an average value of $3470 \mathrm{~kg} D M /$ ha. However, the pastures with $B$. decumbens the average for the rainy season (3485 $\mathrm{kg} \mathrm{DM} / \mathrm{ha}$ ) was superior to that in the dry season (3056 kg DM/ha). The availability of the green fraction of the grasses was influenced negatively by the increase in stocking rate. During the rainy season, there was a higher proportion of grasses, for an estimated stocking rate of $1.17 \mathrm{AU} / \mathrm{ha}$. B. decumbens pastures maintained a higher proportion of green forage and showed a higher nutritive value associated to a higher presence of legumes than in the B. brizantha pastures.
\end{abstract}

Key Words: Brachiaria, IVOMD, green dry matter, leaf:steam ratio, forage legume

\section{Introdução}

Atualmente, somente na região dos Cerrados, estima-se em 45 a 50 milhões de hectares com pastagens cultivadas, sendo $55 \%$ desta área com Brachiaria decumbens e $20 \%$ com B. brizantha
(Macedo, 1995). Entretanto, cerca de 30 milhões de hectares encontram-se em algum grau de degradação, em função do manejo inadequado, principalmente, com o uso de taxas de lotação acima da capacidade de suporte das pastagens e a falta de adubação de manutenção.

\footnotetext{
1 Pesquisa financiada pela Embrapa Gado de Corte e pelo CNPq.

2 Professor do Departamento de Agronomia da UNEMAT, Tangará da Serra, MT, 78300-000. E.mail: robertogiolo@unemat.br

3 Professor do Departamento de Zootecnia da UFV, Viçosa, MG, 36571-000. E.mail: domicion@ufv.br

4 Pesquisador da Embrapa Gado de Corte, Caixa Postal 154, Campo Grande, MS, 79002-970.

5 Eng $^{a}$.-Agra . Doutora em Zootecnia. E.mail: pbrancio@zipmail.com.br

6Zootecnista M.Sc., estudante do Departamento de Zootecnia da UFV, Viçosa, MG, 36571-000.
} 
O uso de leguminosas em pastagens foi sugerido como alternativa para sistemas de produção pecuária com uso reduzido de insumos nitrogenados, como é o caso da região dos Cerrados, mas a dificuldade em manejar duas espécies com características morfofisiológicas distintas, tem dificultado a sua adoção dessa tecnologia.

A curto prazo, vários trabalhos têm demonstrado a superioridade de pastos consorciados sobre aqueles com a mesma gramínea em monocultivo, tanto em termos de produção de forragem quanto de conteúdo de proteína bruta da MS disponível (Favoretto et al., 1983; Pereira et al. 1992; Euclides et al., 1998).

Segundo Cadisch et al. (1994), o manejo adequado do pasto consorciado para aumentar a fixação de $\mathrm{N} 2$ e a reciclagem de $\mathrm{N}$ deve considerar curtos períodos de descanso para melhorar a persistência de leguminosas (maior utilização da gramínea), taxa de lotação adequada (para melhorar a reciclagem do resíduo), uso de leguminosas menos palatáveis (para melhorar a persistência) e de decomposição rápida (baixa relação $\mathrm{C}: \mathrm{N}$ ).

Thomas (1992) afirmou que para pastagens tropicais produzindo 3-22 t/ha.ano de matéria seca (MS), são necessários de 15 a $158 \mathrm{~kg} /$ ha.ano de N por meio da fixação biológica, indicando que, sob estas condições, leguminosas compondo 20 a $45 \%$ da MS da pastagem podem promover sistemas produtivos e sustentáveis, em termos de N.

Leite et al. (1994), estudando sobre estratégias de manejo para pastos consorciados nos Cerrados, observaram que a proporção de leguminosas das pastagens diminuiu com o tempo, entretanto, nas pastagens sob pastejo contínuo, sob pastejo rotacionado 7/21 (dias de pastejo/dias de descanso) e sob pastejo alternado $21 / 21$, mantiveram a proporção de leguminosas variando entre 20 e $40 \%$, enquanto nas pastagens sob pastejo rotacionado $14 / 42$ a proporção de leguminosas caiu para $12 \%$.

Maldonado et al. (1995) estudaram os efeitos de três taxas de lotação, 2,0;2,7 e 3,4 UA/ha, em pastagens de Brachiaria dictyoneura com Desmodium ovalifolium, de Brachiaria dictyoneura com Centrosema macrocarpum e de B. brizantha com $C$. macrocarpum, manejadas sob pastejo rotacionado $6 / 30$ e observaram que a porcentagem de leguminosa na pastagem foi diretamente proporcional à taxa de lotação, quando a leguminosa era competitiva e pouco consumida pelos animais.

$$
\mathrm{O} \text { estilosantes Mineirão (Stylosanthes }
$$

guianensis var. vulgaris cv. Mineirão), foi lançado em 1993 pela Embrapa, como alternativa para formação de pastagens na região dos Cerrados, entretanto, estima-se que apenas $2 \%$ das áreas de pastagens dos Cerrados envolvam consorciações com leguminosas (Macedo, 1995; Zimmer \& Euclides Filho, 1997).

Em função do pequeno número de pesquisas envolvendo esta leguminosa, o presente estudo foi conduzido com o objetivo de avaliar a consorciação do estilosantes Mineirão com as duas principais gramíneas utilizadas nos Cerrados, sob três taxas de lotação.

\section{Material e Métodos}

O experimento foi conduzido na Embrapa Gado de Corte, em Campo Grande, MS, no período de julho de 1998 a abril de 1999.

O padrão climático da região é descrito, segundo Köppen, na faixa de transição entre Cfa e Aw tropical úmido. A precipitação média anualé de $1500 \mathrm{~mm}$, sendo considerados meses de seca, de maio a setembro (30\% da precipitação anual). Os dados meteorológicos do período experimental encontram-se na Tabela 1.

As pastagens, encontram-se em um Latossolo Vermelho-Escuro (LVE), fase cerradão, caracterizado por apresentar textura argilosa, $\mathrm{pH}$ ácido, baixa saturação por bases e baixo teor de fósforo.

Em dezembro de 1995, as pastagens de $B$. decumbens Stapf e de B. brizantha (Hoecht) Stapf cv. Marandu foram renovadas com a introdução do estilosantes Mineirão. O preparo e a correção do solo constaram das seguintes operações: calagem ( $2 \mathrm{t}$ de calcário dolomítico/ha), gradagem, aplicação de adubo (250 kg da fórmula 0:20:20), seguida de duas gradagens com grade niveladora sobre as braquiárias. A semeadura do estilosantes Mineirão foi feita a lanço e as sementes foram compactadas com um rolo. A taxa de semeadura foi de $2,2 \mathrm{~kg} / \mathrm{ha}$ de sementes puras viáveis. As braquiárias retornaram das sementes existentes no solo. Foi adotado o delineamento experimental em blocos casualizados, com os tratamentos em esquema de parcelas subdivididas, com duas repetições. Os tratamentos das parcelas (piquetes) constituíram um fatorial $2 \times 3$, sendo duas gramíneas (B. decumbens e B. brizantha cv. Marandu) em consorciação com $S$. guianensis cv. Mineirão e três taxas de lotação $(0,8 ; 1,2$ e 1,6 UA/ha), e os tratamentos das subparcelas, os meses de amostragem, julho e outubro (época seca), e janeiro e abril (época das águas).

R. Bras. Zootec., v.32, n.1, p.36-46, 2003 
Tabela 1 - Dados meteorológicos mensais da Estação Meteorológica do CNPGC, Campo Grande, MS, no período de junho de 1998 a abril de 1999

Table 1 - Monthly weather data from CNPGC's weather station, Campo Grande, MS, from June 1998 to April 1999

\begin{tabular}{lccccc}
\hline $\begin{array}{l}\text { Mês/Ano } \\
\text { Month/year }\end{array}$ & $\begin{array}{c}\text { Precipitação mensal }(\mathrm{mm}) \\
\text { Rainfall }(\mathrm{mm})\end{array}$ & \multicolumn{3}{c}{$\begin{array}{c}\text { Temperatura média }\left({ }^{\circ} \mathrm{C}\right) \\
\text { Mean temperature }\left({ }^{\circ} \mathrm{C}\right)\end{array}$} & $\begin{array}{c}\text { Umidade relativa do ar (\%) } \\
\text { Relative air moisture (\%) }\end{array}$ \\
\cline { 3 - 5 } & & $\begin{array}{c}\text { Mínima } \\
\text { Minimum }\end{array}$ & $\begin{array}{c}\text { Máxima } \\
\text { Máximum }\end{array}$ & $\begin{array}{c}\text { Média geral } \\
\text { Overall mean }\end{array}$ & \\
\hline $\begin{array}{l}\text { Junho/98 } \\
\text { June/98 }\end{array}$ & 27,90 & 15,64 & 26,83 & 20,03 & 77 \\
$\begin{array}{l}\text { Julho/98 } \\
\text { July/98 }\end{array}$ & 39,00 & 16,96 & 29,46 & 21,65 & 65 \\
$\begin{array}{l}\text { Agosto/98 } \\
\text { August/98 }\end{array}$ & 122,00 & 17,41 & 28,42 & 21,70 & 72 \\
$\begin{array}{l}\text { Setembro/98 } \\
\text { September/98 }\end{array}$ & 115,00 & 18,08 & 29,32 & 22,49 & 72 \\
$\begin{array}{l}\text { Outubro/98 } \\
\text { October/98 }\end{array}$ & 114,40 & 19,64 & 30,30 & 23,91 & 74 \\
$\begin{array}{l}\text { Novembro/98 } \\
\text { November/98 }\end{array}$ & 83,80 & 19,93 & 31,36 & 24,88 & 71 \\
$\begin{array}{l}\text { Dezembro/98 } \\
\text { December/98 }\end{array}$ & 148,30 & 20,40 & 30,45 & 24,71 & 75 \\
$\begin{array}{l}\text { Janeiro/99 } \\
\text { January/99 }\end{array}$ & 198,90 & 20,96 & 31,00 & 24,90 & 80 \\
$\begin{array}{l}\text { Fevereiro/99 } \\
\begin{array}{l}\text { February/99 } \\
\text { Março/99 }\end{array}\end{array}$ & 127,40 & 21,53 & 31,89 & 25,33 & 79 \\
March/99 & 188,10 & 21,44 & 30,93 & 25,01 & \\
\hline
\end{tabular}

Estes piquetes foram mantidos sob pastejo por dois anos. O presente experimento teve início em julho de 1998, após um período de vedação dos piquetes de cerca de 30 dias. As amostragens foram realizadas nos meses de julho e outubro de 1998, correspondendo ao ápice e ao final da época seca, e de janeiro e abril de 1999, correspondendo ao ápice e ao final da época das águas. Utilizaram-se bezerros Nelore, desmamados, com peso vivo médio de $138 \mathrm{~kg}$, sendo distribuídos nos piquetes, de acordo com as respectivas taxas de lotação.

Para se estimar a disponibilidade de forragem, foram tomadas 50 amostras $\left(0,25 \mathrm{~m}^{2}\right)$ ao acaso, em 10 transecções por piquete, sendo o corte feito ao nível do solo. As amostras foram pesadas individualmente, retirando-se uma subamostra, que foi secada a $100^{\circ} \mathrm{C}$, para cálculo da matéria seca (MS).

Para determinação da composição botânica, estas mesmas 50 amostras foram subamostradas, sendo que, de cada dez, formava-se uma amostra composta, de modo a se obter cinco amostras compostas, por piquete. Realizou-se a separação manual dos componentes da forragem colhida, em frações da gramínea verde (lâmina foliar e colmo+bainha) mais material senescente, e da leguminosa verde (folha e caule) e senescente. Considerou-se material senescente aquele completamente seco ou que apresentasse área seca superior a 50\%. As frações das gramíneas e das leguminosas serão chamadas, de uma forma geral: folha, caule (colmo, para gramíneas) e material morto, respectivamente. A proporção de cada fração de componente foi expressa em porcentagem da massa seca total, calculando-se a disponibilidade de cada fração por área, que serviu como base para determinação da composição botânica das pastagens.

Cada fração foi, posteriormente, analisada quanto aos teores de proteína bruta (PB), de fibra em detergente neutro (FDN) e à digestibilidade in vitro da matéria orgânica (DIVMO).

Para as análises bromatológicas das amostras da forragem colhida, utilizou-se a espectroscopia de reflectância do infra-vermelho próximo (NIRS), de acordo com os procedimentos descritos por Marten et al. (1985). Os dados de reflectância das amostras, na faixa de comprimentos de onda de 1100 a $2500 \mathrm{hm}$, foram analisados por um espectrômetro (modelo NR 5000; NIR Systems, Inc., USA), acoplado a um microcomputador. Cerca de 20-25\% do montante das amostras foram analisadas via úmida: proteína bruta, 
conforme AOAC (1990); FDN, conforme Goering \& Van Soest (1970); e DIVMO, conforme Tilley \& Terry (1963) modificado por Moore \& Mott (1974). Os valores obtidos foram utilizados no desenvolvimento de equações de calibração, para cada parâmetro qualitativo, para gramíneas e para leguminosas, separadamente, por meio do programa computacional WINISI, versão 1.02a (Infrasoft International, L.L.C., USA). As melhores equações foram selecionadas com base nos menores errospadrão de calibração (EC) e de validação (EV), considerando-se EV:EC $\leq 1,3$ (Pires \& Prates, 1998), altos coeficientes de determinação (R2) e coeficientes de regressão ( $($ ) com valores próximos de 1,0 (derivados da regressão dos dados da predição com os dados das análises químicas), podendo-se observar seus parâmetros na Tabela 2 .

Os dados foram analisados pelo aplicativo estatístico SAS (SAS, 1990). Para os fatores qualitativos com apenas dois níveis (gramínea, época e mês dentro de época), as médias foram comparadas pelo teste $\mathrm{F}$. Para o fator quantitativo (taxa de lotação), realizou-se a análise de regressão, sendo escolhida a melhor equação ajustada, de acordo com o coeficiente de determinação, significância dos coeficientes de regressão e teste para falta de ajustamento. As interações significativas foram desdobradas, convenientemente. Adotou-se o nível de significância de 5\%.

Tabela 2 - Estatísticas de calibração (c) e de validação (v) para determinação da matéria seca (MS), da proteína bruta (PB), da fibra em detergente neutro (FDN) e da digestibilidade in vitro da matéria orgânica (DIVMO) de amostras de gramíneas e de leguminosas, por meio do NIRS

Table 2 - Statistics of calibration (c) and validation ( $v$ ) to estimate the dry matter (DM), crude protein (CP), neutral detergent fiber (NDF) and in vitro organic matter digestibility (IVOMD) from samples of grasses and legume through NIRS

\begin{tabular}{|c|c|c|c|c|c|c|c|c|c|}
\hline \multirow[t]{2}{*}{$\begin{array}{l}\text { Parâmetro } \\
\text { Parameter }\end{array}$} & \multicolumn{5}{|c|}{$\begin{array}{l}\text { Calibração } \\
\text { Calibration }\end{array}$} & \multicolumn{4}{|c|}{$\begin{array}{l}\text { Validação } \\
\text { Validation }\end{array}$} \\
\hline & $\mathrm{n}$ & $\begin{array}{c}\text { Média } \\
\text { Mean }\end{array}$ & $\begin{array}{c}\text { Desvio } \\
\text { Deviation } \\
\end{array}$ & $\mathrm{E}_{\mathrm{C}}$ & $\mathrm{R}_{2}$ & $\mathrm{n}$ & $\mathrm{E}_{\mathrm{V}}$ & $\mathrm{R}_{2}$ & ß \\
\hline $\begin{array}{l}\text { Gramíneas } \\
\text { Grass }\end{array}$ & & & -- $\%$ & & & & & & \\
\hline $\begin{array}{l}\text { MS } \\
D M\end{array}$ & 167 & 92,1 & 0,7 & 0,2 & 0,90 & 50 & 0,2 & $0,88 \mathrm{a}$ & 1,0 \\
\hline $\begin{array}{l}\mathrm{PB} \\
C P\end{array}$ & 163 & 5,0 & 2,1 & 0,3 & 0,98 & 52 & 0,3 & 0,98 & 1,0 \\
\hline $\begin{array}{l}\text { FDN } \\
N D F\end{array}$ & 158 & 73,6 & 4,3 & 0,9 & 0,96 & 49 & 1,1 & 0,89 & 0,9 \\
\hline $\begin{array}{l}\text { DIVMO } \\
\text { IVOMD } \\
\text { Leguminosas } \\
\text { Legumes }\end{array}$ & 145 & 38,2 & --- \% ------- & 2,3 & 0,94 & 48 & 3,0 & 0,89 & 1,0 \\
\hline $\begin{array}{l}\mathrm{MS} \\
D M\end{array}$ & 194 & 92,4 & 0,9 & 0,2 & 0,94 & 57 & 0,3 & 0,91 & 1,0 \\
\hline $\begin{array}{l}\text { PB } \\
C P\end{array}$ & 202 & 10,7 & 5,5 & 0,5 & 0,99 & 64 & 0,6 & 0,99 & 1,0 \\
\hline $\begin{array}{l}\text { FDN } \\
N D F\end{array}$ & 197 & 64,0 & 13,2 & 1,6 & 0,99 & 61 & 2,0 & 0,98 & 1,0 \\
\hline $\begin{array}{l}\text { DIVMO } \\
\text { IVOMD }\end{array}$ & 190 & 36,6 & 19,7 & 2,6 & 0,98 & 57 & 3,4 & 0,97 & 1,0 \\
\hline
\end{tabular}

a: coeficiente de determinação derivado de regressão linear dos valores preditos contra os valores da análise química.

ß: coeficiente de regressão dos valores preditos contra os valores da análise química.

$\mathrm{n}$ : número de amostras.

E: erro-padrão.

a: coefficient of determination derived from linear regression of predicted values against the values of chemical analysis.

$B$ : coefficient of regression from predicted values against the values from chemical analysis).

$n$ : number of samples.

E: standard error.

R. Bras. Zootec., v.32, n.1, p.36-46, 2003 


\section{Resultados e Discussão}

Durante todo o experimento, independentemente da taxa de lotação, a disponibilidade de matéria seca (MS) foi elevada, mas decaiu em relação aos dados observados em 1996 (Euclides, 1997), cerca de 10\% nas pastagens com $B$. brizantha e $18 \%$ nas pastagens com $B$. decumbens. Este comportamento está de acordo com o padrão apresentado por pastagens exclusivas de braquiárias nesta região, que tendem a apresentar maior produção forrageira no primeiro ano após o estabelecimento, cerca de $30 \%$ superior a dos anos subseqüentes (Leite \& Euclides, 1994; Macedo, 1995). Entretanto, esta queda menos pronunciada na disponibilidade de MS, observada no presente trabalho, pode ser atribuída ao uso do estilosantes Mineirão em consorciação com as braquiárias.

Deve-se considerar que a precipitação acumulada da época seca, no presente trabalho, foi maior do que a média histórica (Tabela 1), para a referida época, sendo que, sob condições normais, provavelmente, a produção forrageira da consorciação $B$. brizantha $\mathrm{x}$ Mineirão seria mais comprometida, de acordo com Euclides (1994).

Houve efeito significativo $(\mathrm{P}<0,05)$ do mês dentro de época do ano e da interação entre gramínea e época sobre a disponibilidade de MS.

Durante a época seca, observou-se maior disponibilidade de MS no mês de julho (3458 kg/ha) do que no mês de outubro $(3120 \mathrm{~kg} / \mathrm{ha})$, devido ao fato das pastagens terem permanecido vedadas durante cerca de 30 dias, antes do início do experimento, possibilitando, assim, maior acúmulo de forragem naquele mês. Na época das águas, a disponibilidade de MS do mês de abril ( $3597 \mathrm{~kg} / \mathrm{ha})$ foi maior do que a do mês de janeiro (3306 kg/ha), mostrando o aumento na produção de MS com o avançar da estação de crescimento, o que está de acordo com as observações feitas por Euclides (1994). Este comportamento, durante a época das águas, foi acompanhado pela maior $(\mathrm{P}<0,05)$ percentagem de colmo da gramínea em abril do que em janeiro, com valores médios de 21,8 e 17,7\%, respectivamente, evidenciando o processo de reprodução e conseqüente alongamento do colmo.

Para pastos consorciados de B. brizantha e Mineirão, não houve diferença $(\mathrm{P}>0,05)$ na disponibilidade de MS entre épocas, enquanto, para pastos consorciados de B. decumbens e Mineirão, a disponibilidade de MS durante as águas foi maior $(\mathrm{P}<0,05)$ que os valores verificados na época seca (Tabela 3 ).
Tabela 3 - Médias das disponibilidades de matéria seca em pastagens consorciadas, durante as épocas da seca e das águas

Table 3 - Dry matter available in mixed pastures during dry and rainy seasons

\begin{tabular}{lcc}
\hline $\begin{array}{l}\text { Pastagem } \\
\text { Pasture }\end{array}$ & \multicolumn{2}{c}{$\begin{array}{c}\text { Disponibilidade de MS }(\mathrm{kg} / \mathrm{ha}) \\
\text { Dry matter availability }(\mathrm{kg} / \mathrm{ha})\end{array}$} \\
\cline { 2 - 3 } & $\begin{array}{c}\text { Águas } \\
\text { Rainy season }\end{array}$ & $\begin{array}{c}\text { Seca } \\
\text { Dry season }\end{array}$ \\
\hline B. decumbens + Mineirão & $3485 \mathrm{Aa}$ & $3057 \mathrm{Bb}$ \\
B. brizantha + Mineirão & $3418 \mathrm{Aa}$ & $3521 \mathrm{Aa}$ \\
\hline
\end{tabular}

$\mathrm{A}>\mathrm{B}$ letras maiúsculas e minúsculas comparam médias nas colunas e nas linhas, respectivamente, pelo teste $F(P<0,05)$. Capital and small letters compare means in column and row, respectively, by $F$ test $(P<.05)$.

Este comportamento, para pastagens com $B$. decumbens, provavelmente, pode ser explicado, em parte, pelo menor acúmulo de material morto durante a seca, de acordo com o observado por Euclides et al. (1993), em pastagens exclusivas desta gramínea.

Em regiões onde ocorre grande acúmulo de material morto, em conseqüência da sazonalidade da produção de MS, o consumo e a produção animal se correlacionam melhor com a disponibilidade da fração verde, de acordo com 't Mannetje \& Ebersohn (1980) e Euclides et al. (2000).

Verificou-se efeito $(\mathrm{P}<0,05)$ de gramínea, de mês dentro de época e da interação entre taxa de lotação e época do ano sobre a disponibilidade de matéria verde seca (MVS) (Tabela 4).

As pastagens com B. decumbens apresentaram maior disponibilidade de MVS do que as pastagens com $\mathrm{B}$. brizantha $(\mathrm{P}<0,05)$, com valores médios de 2185 e $1865 \mathrm{~kg} / \mathrm{ha}$, respectivamente.

$\mathrm{Na}$ época das águas, não se verificou diferença $(\mathrm{P}>0,05)$ entre os meses de amostragem (janeiro e abril), com valor médio de $2017 \mathrm{~kg} /$ ha de MVS, mas durante o período seco, houve maior $(\mathrm{P}<0,05)$ disponibilidade de MVS no mês de julho do que em outubro, $2151 \mathrm{e} 1913 \mathrm{~kg} / \mathrm{ha}$, respectivamente, provavelmente, porque as pastagens ficaram vedadas por cerca de 30 dias antes do início do experimento, em julho.

Durante a época seca, a taxa de lotação não influenciou $(\mathrm{P}>0,05)$ na disponibilidade média de MVS, de $2032 \mathrm{~kg} / \mathrm{ha}$, entretanto, durante a época das águas, ajustou-se uma equação quadrática $(\mathrm{P}<0,05)$, estimando-se menor disponibilidade de MVS, de $1658 \mathrm{~kg} / \mathrm{ha}$, para uma taxa de 1,28 UA/ha (ver rodapé da Tabela 4). 
Tabela 4 - Médias das disponibilidades de matéria verde seca (MVS), nos pastos consorciados, sob diferentes taxas de lotação, durante as épocas da seca e das águas

Table 4 - Green dry matter available (GDM) in mixed pastures at different stocking rates during dry and rainy seasons

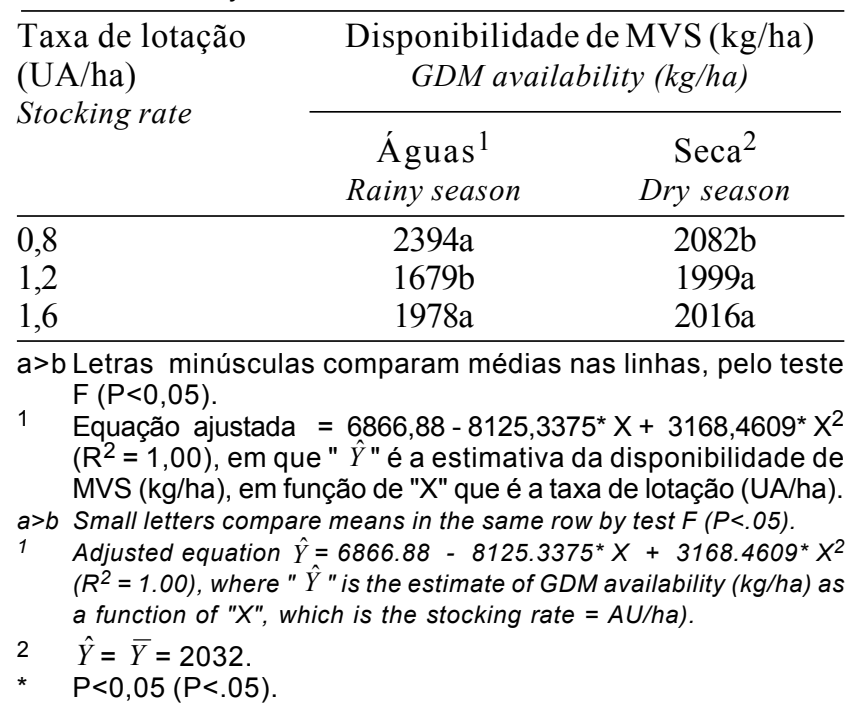

das águas) podem estar relacionados à maior pastejo sobre a gramínea, de acordo com Late et al. (1994).

Nas pastagens com B. brizantha não foi verificada diferença entre meses de uma mesma época, com valores médios de 10,2 e 13,6\% de leguminosa para os meses das épocas seca e das águas, respectivamente. Para os meses de amostragem, entretanto, foram observados maiores proporções de leguminosa nas pastagens com B. decumbens.

O potencial alelopático da $B$. brizantha (Stanizio et al., 1991; Almeida et al., 1997; Souza Filho et al.,
Tal comportamento pode ser explicado pelo efeito quadrático da taxa de lotação sobre a percentagem de leguminosa da pastagem, durante a época das águas, uma vez que a disponibilidade de MVS foi correlacionada $(\mathrm{P}<0,01)$ com a quantidade de leguminosa verde na pastagem $(\mathrm{r}=0,60)$.

Observou-se diminuição da disponibilidade de matéria verde seca do componente gramínea (MVG) com o aumento da taxa de lotação $(\mathrm{P}<0,05)$, estimando-se valores de 1568,1453 e $1338 \mathrm{~kg} /$ ha de MVG $(\hat{Y})$, para as taxas de lotação $(\mathrm{X})$ de $0,8,1,2$ e 1,6 UA/ha, de acordo com a equação ajustada:

$$
\hat{Y}=1799,08-288,3180 * \mathrm{X}\left(\mathrm{R}^{2}=0,99\right) .
$$

Isto pode ser explicado pela preferência dos bovinos por partes verdes da gramínea (folha e colmo), tendo em vista que mais de $90 \%$ da dieta dos animais foi constituída por estas frações (Almeida et al., 2003).

Late et al. (1994) demonstraram que, em pastos consorciados, a pressão de seleção exercida por bovinos sobre partes das gramíneas, especialmente folhas verdes, pode contribuir para a instabilidade dos componentes destas pastagens.

A composição botânica das pastagens, durante os meses de amostragem, é apresentada na Tabela 5.

Houve efeito significativo $(\mathrm{P}<0,05)$ da interação entre gramínea e mês, dentro de época, sobre a percentagem de leguminosa das pastagens. Nas pastagens com $B$. decumbens, verificou-se variação na percentagem de leguminosa durante as épocas do ano; durante a seca foi observado maiores proporções de leguminosa no mês de outubro e, durante as águas, no mês de janeiro, mantendo-se sempre valores superiores a 16,0\%. Estes maiores valores observados em outubro (final da seca) e em janeiro (ápice

Tabela 5 - Médias das percentagens de gramínea (GRA) e de leguminosa (LEG), em pastos consorciados, nos meses de amostragem

Table 5 - Mean percentage of grass (GRA) and legume (LEG) in mixed pastures in the sampling months

\begin{tabular}{|c|c|c|c|c|c|c|c|c|}
\hline \multirow{3}{*}{$\begin{array}{l}\text { Variáveis } \\
\text { Variables }\end{array}$} & \multicolumn{4}{|c|}{ B. brizantha + Mineirão } & \multicolumn{4}{|c|}{ B. decumbens + Mineirão } \\
\hline & \multicolumn{2}{|c|}{$\begin{array}{c}\text { Seca } \\
\text { Dry season }\end{array}$} & \multicolumn{2}{|c|}{$\begin{array}{c}\text { Águas } \\
\text { Rainy season }\end{array}$} & \multicolumn{2}{|c|}{$\begin{array}{c}\text { Seca } \\
\text { Dry season }\end{array}$} & \multicolumn{2}{|c|}{$\begin{array}{c}\text { Águas } \\
\text { Rainy season }\end{array}$} \\
\hline & $\begin{array}{l}\text { Jul. } \\
\text { Jul. }\end{array}$ & $\begin{array}{l}\text { Out. } \\
\text { Oct. }\end{array}$ & $\begin{array}{l}\text { Jan. } \\
\text { Jan. }\end{array}$ & $\begin{array}{l}\text { Abr. } \\
\text { Apr. }\end{array}$ & $\begin{array}{l}\text { Jul. } \\
\text { Jul. }\end{array}$ & $\begin{array}{l}\text { Out. } \\
\text { Oct. }\end{array}$ & $\begin{array}{l}\text { Jan. } \\
\text { Jan. }\end{array}$ & $\begin{array}{l}\text { Abr. } \\
A p r .\end{array}$ \\
\hline $\begin{array}{l}\text { GRA }(\%) \\
\text { LEG }(\%)\end{array}$ & $\begin{array}{c}92,3 \mathrm{Aa} \\
7,7 \mathrm{Ba}\end{array}$ & $\begin{array}{l}87,4 \mathrm{Aa} \\
12,6 \mathrm{Ba}\end{array}$ & $\begin{array}{l}83,9 \mathrm{Aa} \\
16,1 \mathrm{Ba}\end{array}$ & $\begin{array}{l}89,0 \mathrm{Aa} \\
11,0 \mathrm{Ba}\end{array}$ & $\begin{array}{l}84,0 \mathrm{Ba} \\
16,0 \mathrm{Ab}\end{array}$ & $\begin{array}{l}67,5 \mathrm{Bb} \\
32,5 \mathrm{Aa}\end{array}$ & $\begin{array}{l}63,6 \mathrm{Bb} \\
36,4 \mathrm{Aa}\end{array}$ & $\begin{array}{l}70,1 \mathrm{Ba} \\
29,9 \mathrm{Ab}\end{array}$ \\
\hline
\end{tabular}

$A>B$, na linha, comparam gramíneas em mês da mesma época; a>b, na linha, comparam meses de uma época na mesma gramínea, pelo teste $F(P<0,05)$.

$A>B$, in row, grass are compared by month in the same season by the test $F(P<.05)$; $a>b$, in row, months are compared by a season with the same grass by test $F(P<.05)$.

R. Bras. Zootec., v.32, n.1, p.36-46, 2003 
2000), aliado ao porte ereto e à sua competitividade (Barcellos et al., 2000), podem ser considerados como possíveis causas da menor presença e persistência do estilosantes Mineirão no consórcio com esta gramínea.

Foi observado efeito da interação entre taxa de lotação e época do ano sobre a porcentagem de leguminosa das pastagens. Durante a época seca, não se verificou diferença na proporção de leguminosa das pastagens entre taxas de lotação, com valor médio de $17,2 \%$, entretanto, durante as águas, foi observado efeito quadrático $(\mathrm{P}<0,05)$ da taxa de lotação sobre a porcentagem de leguminosa das pastagens, com valor estimando de menor porcentagem de leguminosa na pastagem $(13,9 \%)$ para uma taxa de 1,17 UA/ha (Tabela 6).

As relações folha/colmo e material vivo/morto de gramíneas, das pastagens consorciadas, durante as épocas da seca e das águas, são apresentados na Tabela 7.

Na relação folha/colmo de gramíneas, verifica-se que não houve diferenças entre épocas $(\mathrm{P}>0,05)$, nas pastagens com $B$. brizantha, com a predominância de folhas sobre colmo. Já nas pastagens com $B$. decumbens, houve menor $(\mathrm{P}<0,05)$ proporção de folha, na época das águas, demonstrando o padrão de alongamento do colmo, mais característico nesta

Tabela 6 - Médias das percentagens de leguminosa, em pastos consorciados, sob três taxas de lotação, durante as épocas da seca e das águas

Table 6 - Mean percentage of legume in mixed pastures under three stocking rates during the dry and the rainy seasons

Taxa de lotação (UA/ha) Leguminosa na pastagem (\%) Stocking rate (AU/ha)

\begin{tabular}{lcc} 
Stocking rate $($ AU/ha) & \multicolumn{2}{c}{ Legume covering (\%) } \\
\cline { 2 - 3 } & $\begin{array}{c}\text { Águas }{ }^{2} \\
\text { Rainy season }\end{array}$ & $\begin{array}{c}\text { Seca }^{2} \\
\text { Dry season }\end{array}$ \\
\hline 0,8 & $26,3 \mathrm{a}$ & $16,8 \mathrm{~b}$ \\
1,2 & $14,0 \mathrm{a}$ & $15,5 \mathrm{a}$ \\
1,6 & $29,8 \mathrm{a}$ & $19,4 \mathrm{~b}$ \\
\hline
\end{tabular}

$a>b$ Letras comparam médias nas linhas, pelo teste $F(P<0,05)$. $a>b \quad$ Letters compare means of the rows by test $F(P<.05)$.

1 Equação ajustada $Y=135,24-206,5359^{*} X+87,9102^{*} X^{2}$ $\left(\mathrm{R}^{2}=1,00\right)$, em que " $Y$ " é a estimativa da porcentagem de leguminosa da pastagem, em função de "X", que é a taxa de lotação (UA/ha).

1 Adjusted equation $\hat{Y}=135.24-206.5359^{*} X+87.9102^{*} X^{2}\left(R^{2}=\right.$ 1.00 ), where " $\hat{Y}$ " is the estimate of percentage of legume in the pasture as a function of " $X$ " which is the stocking rate (AU/ha).

$2 \hat{Y}=\bar{Y}=17,2$.

* $\quad \mathrm{P}<0,05(\mathrm{P}<.05)$.

R. Bras. Zootec., v.32, n.1, p.36-46, 2003 gramínea, durante a estação de crescimento. A relação folha/colmo na época seca, nas pastagens de $B$. decumbens, foi superior aos valores mostrados por Rao et al. (1996), de 1,31 e 0,77 para B. brizantha e B. decumbens, respectivamente.

Quanto à relação material vivo/morto de gramíneas, verifica-se o mesmo comportamento observado para a relação folha/colmo, quando se comparam as épocas do ano em cada consorciação, entretanto, pode-se observar que as pastagens com $B$. decumbens apresentaram maior $(\mathrm{P}<0,05)$ proporção de material vivo de gramínea, na época seca, do que as pastagens com $B$. brizantha, demonstrando comportamento semelhante ao de pastagens exclusivas destas gramíneas, de acordo com os resultados de Euclides et al. (1993).

Houve efeito linear $(\mathrm{P}<0,05)$ decrescente da taxa de lotação $(\mathrm{X})$ sobre a porcentagem de colmo de gramínea $(\hat{Y})$, estimando-se valores de 22,$3 ; 21,5 \mathrm{e}$ $20,7 \%$, para as taxas de 0,$8 ; 1,2$; e $1,6 \mathrm{UA} / \mathrm{ha}$, respectivamente, de acordo com a equação ajustada

$$
\hat{Y}=23,95-2,0263 * \mathrm{X}\left(\mathrm{R}^{2}=0,92\right)
$$

Observou-se efeito significativo $(\mathrm{P}<0,05)$ das interações entre espécie de gramínea e época do ano sobre as percentagens de folha e de material morto de gramínea, e de caule de leguminosa (Tabela 8). Houve efeito significativo $(\mathrm{P}<0,05)$ da gramínea em consórcio sobre a fração folha de leguminosa da pastagem, sendo que as pastagens com B. decumbens apresentaram maior porcentagem de folha de leguminosa do que as pastagens com B. brizantha.

Os valores nutritivos da forragem disponível e das folhas de gramínea foram influenciados $(\mathrm{P}<0,05)$ pelo mês dentro da época do ano. Pode-se observar que o teor de proteína bruta da forragem disponível não variou durante a seca, mas sofreu diminuição no final da época das águas (abril), quando as gramíneas estão no processo final de alongamento do colmo; conseqüentemente, foi observado aumento no teor de FDN. Quanto à DIVMO, não se verificaram alterações na época seca, entretanto, na época das águas, foi menor em janeiro, quando as condições climáticas favorecem o crescimento da pastagem e, conseqüentemente, há maior deposição de parede celular, do que em abril (Tabela 9).

Para a fração folha de gramínea, os menores valores de proteína bruta, FDN e DIVMO observados no final da época seca (outubro) e no ápice da 
Tabela 7 - Médias das relações folha/colmo ( $\mathrm{F}: \mathrm{C})$ e material vivo/morto ( $\mathrm{V}: \mathrm{M})$ de gramíneas, em pastos consorciados, nas épocas da seca e das águas

Table 7 - Mean ratios of leaf:stem (L:S) and live:dead matter (L:D) ratios on grass in mixed pasture in the dry and rainy seasons

Características

Characteristics
B. brizantha + Mineirão

\begin{tabular}{|c|c|c|c|}
\hline $\begin{array}{c}\text { Águas } \\
\text { Rainy season }\end{array}$ & $\begin{array}{c}\text { Seca } \\
\text { Dry season }\end{array}$ & $\begin{array}{c}\text { Águas } \\
\text { Rainy season }\end{array}$ & $\begin{array}{c}\text { Seca } \\
\text { Dry season }\end{array}$ \\
\hline $1,3 \mathrm{Aa}$ & $1,4 \mathrm{Aa}$ & $0,7 \mathrm{Bb}$ & $1,5 \mathrm{Aa}$ \\
\hline $1,1 \mathrm{Aa}$ & $1,0 \mathrm{Ba}$ & $1,1 \mathrm{Ab}$ & $2,0 \mathrm{Aa}$ \\
\hline
\end{tabular}

$A>B$, na linha, comparam gramíneas na mesma época do ano; $a>b$, na linha, comparam épocas do ano para a mesma gramínea, pelo teste $\mathrm{F}(\mathrm{P}<0,05)$.

$A>B$, in row, grass are compared in the same season; $a>b$, in row, seasons are compared to the same grass by $F$ test $(P<.05)$

Tabela 8 - Médias das percentagens de folha, de caule e de material morto da gramínea e da leguminosa, em pastos consorciados, nas épocas da seca e das águas

Table 8 - Mean percentage of leaf, stem and dead matter from grass and legume in mixed pasture in the dry and rainy seasons

\begin{tabular}{|c|c|c|c|c|}
\hline \multirow{2}{*}{$\begin{array}{l}\text { Componente } \\
\text { Component }\end{array}$} & \multicolumn{2}{|c|}{ B. brizantha + Mineirão } & \multicolumn{2}{|c|}{ B. decumbens + Mineirão } \\
\hline & $\begin{array}{c}\text { Águas } \\
\text { Rainy season }\end{array}$ & $\begin{array}{c}\text { Seca } \\
\text { Dry season }\end{array}$ & $\begin{array}{c}\text { Águas } \\
\text { Rainy season }\end{array}$ & $\begin{array}{c}\text { Seca } \\
\text { Dry season }\end{array}$ \\
\hline \multicolumn{5}{|l|}{ Gramínea } \\
\hline Grass & \multicolumn{2}{|c|}{----------------\%\%--------------- } & \multicolumn{2}{|c|}{---------------"\%o-------------- } \\
\hline $\begin{array}{l}\text { Folha (Leaf) } \\
\text { Colmo (Stem) }\end{array}$ & $\begin{array}{l}23,9 \mathrm{Ab} \\
19,3 \mathrm{Aa}\end{array}$ & $\begin{array}{l}25,7 \mathrm{Ba} \\
19,6 \mathrm{Aa}\end{array}$ & $\begin{array}{l}14,3 \mathrm{Bb} \\
20,3 \mathrm{Aa}\end{array}$ & $\begin{array}{l}29,6 \mathrm{Aa} \\
20,4 \mathrm{Aa}\end{array}$ \\
\hline $\begin{array}{l}\text { Morto (Dead) } \\
\text { Leguminosa }\end{array}$ & $43,3 \mathrm{Aa}$ & $44,6 \mathrm{Aa}$ & $32,2 \mathrm{Ba}$ & $25,7 \mathrm{Bb}$ \\
\hline Legume & \multicolumn{2}{|c|}{--------------○\%"-------------- } & \multicolumn{2}{|c|}{--------------_\%-------------- } \\
\hline Folha (Leaf) & $2,3 \mathrm{Ba}$ & 2,3 $\mathrm{Ba}$ & 6,6 Aa & $6,9 \mathrm{Aa}$ \\
\hline Caule (Stem) & $8,5 \mathrm{Ba}$ & $6,5 \mathrm{Ba}$ & $21,9 \mathrm{Aa}$ & $14,1 \mathrm{Ab}$ \\
\hline Morto (Dead) & $2,7 \mathrm{Ba}$ & $1,3 \mathrm{Bb}$ & $4,7 \mathrm{Aa}$ & $3,3 \mathrm{Ab}$ \\
\hline
\end{tabular}

$\mathrm{A}>\mathrm{B}$, na linha, comparam gramíneas na mesma época do ano; a>b, na linha, comparam épocas do ano para a mesma gramínea, pelo teste $\mathrm{F}(\mathrm{P}<0,05)$.

$A>B$, in row, grass are compared in the same season, $a>b$, in row, seasons are compared to the same grass by test $F(P<.05)$.

época das águas (janeiro), período de crescimento mais intenso da gramínea, podem estar relacionados a um efeito de diluição. As gramíneas apresentaram diferenças $(\mathrm{P}<0,05)$ no teor de proteína bruta da matéria seca total disponível, sendo os valores maiores nas pastagens com $B$. decumbens do que nas de capimMarandu, 7,3 e 4,9\%, respectivamente (Tabela 10).

Houve efeito significativo $(\mathrm{P}<0,05)$ da gramínea e da época do ano sobre o teor de FDN da forragem disponível. Os valores foram maiores nas águas do que na seca, 78,8 e 77,5\%, respectivamente. Nas pastagens, os valores médios, foram maiores na $B$. brizantha que nas com $B$. decumbens, 79,3 e 77,0\%, respectivamente.

Houve efeito significativo $(\mathrm{P}<0,05)$ da interação entre gramínea e época do ano sobre a DIVMO das frações folha e colmo da forragem disponível. Durante a época das águas, não houve diferença na DIVMO, com valor médio de $33,7 \%$, entretanto, durante a seca, as pastagens com B. decumbens apresentaram maior DIVMO que as com B. brizantha, 38,2 e $34,0 \%$, respectivamente.

Para a fração folha de gramínea, observou-se efeito significativo $(\mathrm{P}<0,05)$ da interação entre espécie de gramínea e época do ano sobre os teores de proteína bruta e de FDN, conforme pode ser observado na Tabela 10.

O valor nutritivo da leguminosa sofreu maior variação entre épocas do ano do que entre consorciações com espécies de gramínea. Deve-se destacar que, nas pastagens com B. decumbens, a forragem disponível e as folhas da gramínea apresentaram teores de proteína bruta sempre superiores a 7,0\%, valor abaixo do qual, segundo Minson (1990), 
Tabela 9 - Médias dos teores de proteína bruta (PB), de fibra em detergente neutro (FDN) e de digestibilidade in vitro da matéria orgânica (DIVMO) da MS disponível e de folhas de gramínea, nos meses de amostragem

Table 9 - Mean percentage of crude protein (CP), neutral detergent fiber (NDF) and in vitro organic matter digestibility (IVOMD) of the available DM and leaves of grass in the sampling months

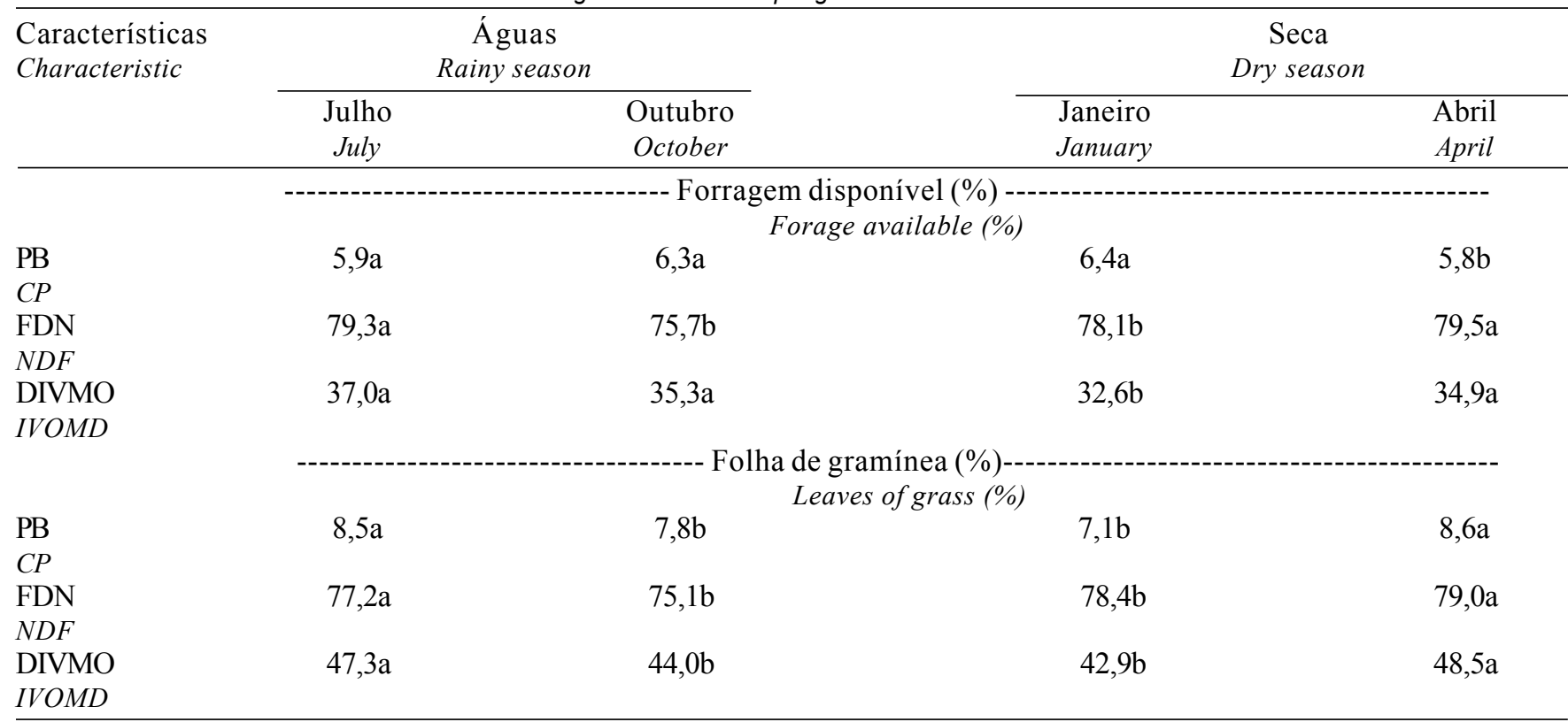

$a>b$ Letras, na linha, comparam meses dentro de cada época, pelo teste $F(P<0,05)$.

$a>b$ Letters in row compare months in each season by the test $F(P<.05)$.

Tabela 10 - Médias dos teores de proteína bruta (PB), de fibra em detergente neutro (FDN) de digestibilidade in vitro da matéria orgânica (DIVMO) da forragem disponível e de folhas das gramíneas, durante as épocas seca e das águas

Table 10 - Mean percentage of crude protein (CP), neutral detergent fiber (NDF) and in vitro organic matter digestibility (IVOMD) from $D M$ available and leaves of grass during dry and rainy seasons

\begin{tabular}{|c|c|c|c|c|}
\hline \multirow{2}{*}{$\begin{array}{l}\text { Características } \\
\text { Characteristics }\end{array}$} & \multicolumn{2}{|c|}{ B. brizantha + Mineirão } & \multicolumn{2}{|c|}{ B. decumbens + Mineirão } \\
\hline & $\begin{array}{c}\text { Águas } \\
\text { Rainy season }\end{array}$ & $\begin{array}{c}\text { Seca } \\
\text { Dry season }\end{array}$ & $\begin{array}{c}\text { Águas } \\
\text { Rainy season }\end{array}$ & $\begin{array}{c}\text { Seca } \\
\text { Dry season }\end{array}$ \\
\hline & -- & $\begin{array}{r}\text { Forragem c } \\
\text { Avail }\end{array}$ & $\begin{array}{l}\text { \%)------------- } \\
\text { (\%) }\end{array}$ & --------- \\
\hline $\begin{array}{l}\text { PB } \\
C P\end{array}$ & $5,0 \mathrm{Bb}$ & $4,8 \mathrm{Bb}$ & $7,2 \mathrm{Aa}$ & $7,4 \mathrm{Aa}$ \\
\hline $\begin{array}{l}\text { FDN } \\
N D F\end{array}$ & 79,9Aa & $78,7 \mathrm{Ab}$ & $77,8 \mathrm{Ba}$ & $76,3 \mathrm{Bb}$ \\
\hline DIVMO & 33,9Aa & $34,0 \mathrm{Ba}$ & $33,6 \mathrm{Ab}$ & $38,2 \mathrm{Aa}$ \\
\hline $1 V O M D$ & $---\cdot$ & $\begin{array}{r}\text {-- Folha de } \\
\text { Led }\end{array}$ & 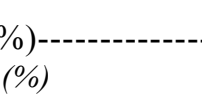 & ----------- \\
\hline $\begin{array}{l}\text { PB } \\
C P\end{array}$ & $6,8 \mathrm{Bb}$ & 7,7Ba & $8,9 \mathrm{Aa}$ & $8,6 \mathrm{Aa}$ \\
\hline $\begin{array}{l}\text { FDN } \\
N D F\end{array}$ & $79,4 \mathrm{Aa}$ & $76,4 \mathrm{Ab}$ & $77,9 \mathrm{Ba}$ & $76,0 \mathrm{Ab}$ \\
\hline DIVMO & $44,7 \mathrm{Ba}$ & $44,6 \mathrm{Ba}$ & $46,7 \mathrm{Aa}$ & $46,7 \mathrm{Aa}$ \\
\hline
\end{tabular}

IVOMD

A>B, na linha, comparam gramíneas na mesma época do ano; $a>b$, na linha, comparam épocas do ano para a mesma gramínea, pelo teste $F(P<0,05)$.

$A>B$, in row, grass are compared in the same season; $a>b$, in row, seasons are compared to to same grass by test $F(P<.05)$. 
limitaria o consumo voluntário e, consequentemente, a produção animal.

De modo geral, os atributos qualitativos da forragem disponível e de folhas de gramínea foram superiores, em certas épocas do ano, para as pastagens com B. decumbens, indicando melhor valor nutritivo, o que, provavelmente, influenciou positivamente a produção animal (Almeida et al., 2002).

\section{Conclusões}

Nas pastagens $\operatorname{com} B$. brizantha, a disponibilidade de matéria seca não variou entre épocas do ano.

Nas pastagens com B. decumbens, a disponibilidade de matéria seca foi maior na época das águas.

Os pastos consorciados de $B$. decumbens com $S$. guianensis cv. Mineirão apresentaram maior proporção de forragem verde, de melhor valor nutritivo, e maior porcentagem de leguminosa do que as consorciações com $B$. brizantha.

A taxa de lotação influenciou negativamente na disponibilidade de matéria verde seca da gramínea.

\section{Literatura Citada}

ALMEIDA, A.R.P.; LUCCHESI, A.A.; ABBADO, M.R. Efeito alelopático de espécies de Brachiaria Griseb. sobre algumas leguminosas forrageiras tropicais. II. Avaliações em casa de vegetação. Boletim da Indústria Animal, v.54, n.2, p.45-54, 1997.

ALMEIDA, R.G.; NASCIMENTO JR., D.; EUCLIDES, V.P.B. et al. Produção animal em pastos consorciados sob três taxas de lotação, no Cerrado. Revista Brasileira de Zootecnia, v.31, n.2, p.852-857, 2002 (Suplemento).

ALMEIDA, R.G.; EUCLIDES, V.P.B.; NASCIMENTO JR., D.; et al. Consumo, composição botânica e valor nutritivo da dieta de bovinos em pastos tropicais consorciados sob três taxas de lotação. Revista Brasileira de Zootecnia, v.32, n.1, p.29-35, 2003.

ASSOCIATION OF OFFICIAL ANALYTICAL CHEMISTS AOAC. Official methods of analysis. Arlington, v.1, p.72-74, 1990.

BARCELLOS, A.O.; ANDRADE, R.P.; KARIA, C.T. et al. Potencial e uso de leguminosas forrageiras dos gêneros Stylosanthes, Arachis e Leucaena. In: SIMPÓSIO SOBRE MANEJO DA PASTAGEM, 17., 2000, Piracicaba. Anais... Piracicaba: Fundação de Estudos Agrários “Luiz de Queiroz”, 2000. p.297-357.

CADISCH, G.; SCHUNKE, R.M.; GILLER, K.E. Nitrogen cycling in a pure grass pasture and a grass-legume mixture on a red latosol in Brazil Tropical Grasslands, v.28, n.1, p.43-52, 1994.

EMPRESA BRASILEIRA DE PESQUISA E AGROPECUÁRIA EMBRAPA. Recomendações para o estabelecimento e utilização do Stylosanthes guinensis cv Mineirão. Planaltina/ Campo Grande, 1993. 6p. (EMBRAPA-CPAC. Comunicado Técnico, 67; EMBRAPA-CNPGC. Comunicado Técnico, 49).

EUCLIDES, V.P.B. Algumas considerações sobre manejo das pastagens. Campo Grande: EMBRAPA-CNPGC, 1994. 31p. (Documento, 57).
EUCLIDES, V.P.B. Relatório de subprojeto. Campo Grande: EMBRAPA-CNPGC, 1997. 5p. (Subprojeto, 06.0.94.172.26).

EUCLIDES, V.P.B.; CARDOSO, E.G.; MACEDO, M.C.M. et al. Consumo voluntário de Brachiaria decumbens cv. Basilisk e Brachiaria brizantha cv. Marandu sob pastejo. Revista Brasileira de Zootecnia, v.29, n.6, p.2200-2208, 2000 (Suplemento 2).

EUCLIDES, V.P.B.; MACEDO, M.C.M.; OLIVEIRA, M.P. Produção de bovinos em pastagens de Brachiaria spp. consorciadas com Calopogonium mucunoides nos cerrados. Revista Brasileira de Zootecnia, v.27, n.2, p. 238-245, 1998.

EUCLIDES, V.P.B.;ZIMMER, A.H.; OLIVEIRA, M.P. Evaluation of Brachiaria decumbens and Brachiaria brizantha under grazing. In: INTERNATIONAL GRASSLAND CONGRESS, 17. 1993, Palmerston North. Proceedings... Palmerston North: New Zealand Grassland Association, 1993. p.1997-1998.

FAVORETTO, V.; GODOI, P.A.; EZEQUIEL, J.M.B. et al. Lotação e utilização de nitrogênio ou de leguminosas em pastagens de capim-colonião sobre o ganho de peso vivo de novilhos de corte. Pesquisa Agropecuária Brasileira, v.18, n.1, p.79-84, 1983.

GOERING, H.K.; Van SOEST, P.J. Forage fiber analysis apparatus, reagents, procedures and some applications. Washington, DC: USDA, 1970. 20 p. (USDA. Agricultural Handbook, 379).

LATE, T.; GARDENER, C.J.; ASH, A.J. Diet selection in six Stylosanthes-grass pastures and its implications for pasture stability. Tropical Grasslands, v.28, n.2, p. 109-119, 1994.

LEITE, G.G.; EUCLIDES, V.P.B. Utilização de pastagens de Brachiaria spp. In: PEIXOTO, A.M. et al. (Eds.). SIMPÓSIO SOBRE MANEJO DA PASTAGEM, 11., Piracicaba, 1994. Anais... Piracicaba: Fundação de Estudos Agrários "Luiz de Queiroz", 1994. p.267-297.

LEITE, G.G.; SPAIN, J.M.; VILELA, L. et al. Estratégias de manejo de pastagens consorciadas nos Cerrados. In: EMBRAPA. Relatório técnico anual do Centro de Pesquisa Agropecuária dos Cerrados. Planaltina, DF: EMBRAPA-CPAC, 1994. p.301-304.

MACEDO, M.C.M. Pastagens no ecossistema cerrados: pesquisa para o desenvolvimento sustentável. In: SIMPÓSIO SOBRE PASTAGENS NOS ECOSSISTEMAS BRASILEIROS: PESQUISAS PARA O DESENVOLVIMENTO SUSTENTÁVEL, Brasília, 1995. Anais... Brasília: Sociedade Brasileira deZootecnia, 1995. p.28-62.

MALDONADO, H.; KELLER-GREIN, G.; NASCIMENTO JR., D.; REGAZZI, A.J. Produção de pastagens associadas sob três taxas de lotação. Pasturas Tropicales, v.17, n.3, p.23-26, 1995.

MANNETJE, L. 't.; EBERSOHN, J.P. Relations between sward characteristics and animal production. Tropical Grasslands, v.14, n.3, p.273-280, 1980.

MARTEN, G.C.; SHENK, J.S.; BARTON II, F.E. Near infrared reflectance spectroscopy (NIRS), analysis of forage quality. Washington: USDA, ARS, 1985. 110 p. (Agriculture Handbook, 643).

MINSON, D.J. Forage in ruminant nutrition. Queensland: Academic Press, 1990. 483p.

MOORE, J.E.; MOTT, G.O. Recovery of residual organic matter from in vitro digestion of forages. Journal of Dairy Science, v.57, n.10, p.1258-1259, 1974.

PEREIRA, J.M.; NASCIMENTO JR., D.; SANTANA, J.R. et al. Teor de proteína bruta e digestibilidade in vitro da matéria seca da forragem disponível e da dieta selecionada por bovinos em pastagem de Brachiaria humidicola (Rendle) Schweickt, em monocultivo ou consorciado com leguminosas, submetida a diferentes taxas de lotação. Revista da Sociedade Brasileira de Zootecnia, v.21, n.1, p.104-117, 1992. 
PIRES, F.F.; PRATES, E.R. Uso da técnica da espectrofotometria de reflectância no infravermelho proximal (NIRS) na predição da composição química da alfafa (Medicago sativa, L.). Revista Brasileira de Zootecnia, v.27, n.6, p.1076-1081, 1998.

RAO, I.M.; KERRIDGE, P.C.; MACEDO,M.C.M. Nutritional requirements of Brachiaria and adaptation to acid soils. In: MILES, J.W.; MAASS, B.L.; VALLE, C.B. (Eds.). Brachiaria: biology, agronomy, and improvement. Cali, CIAT/Campo Grande, EMBRAPA-CNPGC, 1996. p.53-71.

SAS. INSTITUTE INC. SAS/STAT User's guide. Version 6,4 ed., v.1, Cary, NC: SAS Institute Inc., 1990. 943 p.

SOUZA FILHO, A.P.S.; ALVES, S.M.; DUTRA, S. Variações na atividade potencialmente alelopática do capim-Marandú em função do estádio de desenvolvimento das plantas. In: NASCIMENTO JR. et al. (Eds.). REUNIÃO DA SOCIEDADE BRASILEIRA DE ZOOTECNIA, 37., Viçosa, MG, 2000. Anais... Viçosa, MG: Sociedade Brasileira de Zootecnia, 2000. CD-ROM Forragicultura. FOR-0733.

STANIZIO, R.M.; LEITE, G.G.; VILELA, L. Efeito alelopático de Brachiaria brizantha cv. Marandú sobre o crescimento de plântulas de quatro leguminosas forrageiras. In: REUNIÃO DA SOCIEDADE BRASILEIRA DE ZOOTECNIA, 28., João Pessoa, 1993. Anais... João Pessoa: Sociedade Brasileira de Zootecnia, 1991. p.95.
THOMAS, R.J. The role of the legume in the nitrogen cycle of productive and sustainable pastures. Grass and Forage Science, v.47, p.133-142, 1992.

TILLEY, J.M.A.; TERRY, R.A. A two-stage technique for the in vitro digestion of forage crops. Journal of the British Grassland Society, v.18, p.104-111, 1963.

ZIMMER, A.H.; EUCLIDES FILHO, K. As pastagens e a pecuária de corte brasileira. In: SIMPÓSIO INTERNACIONAL SOBRE PRODUÇÃO ANIMAL EM PASTEJO, 1997, Viçosa, MG. Anais... Viçosa, MG: Universidade Federal de Viçosa, 1997. p.349-379.

Recebido em: 28/08/01

Aceito em: 26/08/02 